\title{
SAMPLE-SPECIFIC ODONTOMETRIC SEX ESTIMATION: A METHOD WITH POTENTIAL APPLICATION TO BURNED REMAINS
}

\begin{abstract}
Metric features are often the only preserved sexually dimorphic features to allow sex estimation in burned human remains, but this is complicated by heat-induced dimensional changes. The potential of odontometry for sex estimation was investigated. A sample of permanent lower second pre-molars from 20 males and 20 females was experimentally burned at $900^{\circ} \mathrm{C}$ to assess heat-induced changes in the sexual dimorphism of seven dimensions of the cementum-enamel junction and the root. Four of them, cementum-enamel junction perimeter; mesiodistal, buccolingual and perimeter at the mid-root level, were investigated for the first time. Also, five measurements combining some of the isolated standard measurements were investigated. Additionally, 10 permanent upper central incisors and 10 permanent lower first molars were experimentally burned at $400^{\circ}$ and $700^{\circ} \mathrm{C}$ to document heat-induced dimensional changes and serve as comparison with the $900^{\circ} \mathrm{C}$ sample. Results showed that most of the standard measurements, although presenting significant sex differences, were not reliable enough to allow for correct sex classifications close to $100 \%$ both before and after the burning. Nonetheless, the perimeter at the cementum-enamel junction and the combined measurements of the mesiodistal and buccolingual diameters, at the same level, were quite promising in the post-burning analysis with correct sex classifications above $80 \%$. At $900^{\circ} \mathrm{C}$, females were slightly more affected by shrinkage in this measure than males thus artificially increasing sexual dimorphism after burning. Therefore, and although additional research is needed, this feature was not discarded as having potential for skeletal sex estimation.
\end{abstract}

Keywords: Biological anthropology; sex estimation; odontometry; teeth; Cremated remains.

Introduction

Burned human skeletal remains are frequently found in both archaeological and forensic contexts, as the result of cremation practices, accidents, foul play or natural disasters [1]. Heat can induce several changes in skeletal tissues but these may nonetheless provide us with important information regarding the circumstances of death and the combustion conditions [1-3]. For example, heat-induced changes can be used to infer the approximate maximum temperature [4-6]. Regrettably, the usefulness of burned skeletal remains for the estimation of sex is not as simple. Heat-induced changes and fragmentation often prevent sex estimation based on the most sexually dimorphic features such as the pelvis $[7,8,72]$. Therefore, alternative methods must be investigated. Teeth are very important in any bioanthropological analysis due to their fair resistance to physical and chemical insults [9-20]. Therefore, their potential for sex estimation based on burned remains is clearly worth of investigation. 
Metric sex estimation of burned skeletal remains can basically be achieved in four different ways. First, a shrinkage correction factor may be used according to the extent of heat-induced change which is usually predicted by resorting to the interpretation of chromatic changes since these are approximately correlated to the maximum temperature at which bones have been subjected to $[3,5,21,22,23$, 24]. For example, Buikstra and Swegle [25] proposed a 10\% shrinkage correction factor for calcined bones. Second, again based mainly on chromatic changes, the interval of the measurement can be enlarged in function of the predictable heat-induced dimensional change affecting a bone or tooth [11]. The upper bound is calculated assuming that the bone was affected by maximum possible shrinkage while the lower bound is calculated assuming that the bone was affected by maximum possible expansion [26]. Both correction factors are documented in the literature according to bone and burning intensity [e.g. 4]. Third, metric references obtained from samples of burned skeletal remains can be applied directly to bones burned at similar intensities [27-29, 30-33]. Finally, sample-specific metric references can be obtained when large samples composed of remains burned at similar burning intensities are available. All approaches are somewhat problematic. For example, the enlargement of the estimation confidence interval, may be quite large and have low precision. Also, heat-induced dimensional changes are too variable thus taking out some of the reliability of the remaining approaches [34]. Nonetheless, metric analysis is not without value. Besides allowing for univariate sex estimation, an aspect extremely useful in usually very fragmented burned remains that dispenses a more systemic analysis of the skeleton, it allows to identify very masculine features. In other words, when very large features are found despite heat-induced shrinkage, a male classification can be more confidently attributed to the individual.

Odontometry has been demonstrated to provide reliable sex estimation, particularly in poorly preserved and highly fragmented skeletal remains, as is often the case for assemblages comprising burned skeletal remains $[18,35-42]$. In the vast majority of cases, the standard measurements used for that purpose are the mesiodistal (MD) and the buccolingual (BL) crown diameters of permanent teeth. Several authors have demonstrated that these dimensions have significant sexual dimorphism within a population [40, 4353]. However, similar investigations regarding the dental roots have been much less frequent [52, 54] which is somewhat surprising given that crown measurements present obvious problems. Slight crown rotations can lead to considerable inter- and intra-observation variation [55, 56]. In addition, tooth wear may prevent measurements, especially the MD diameter [52, 56-58]. Dental calculus can also prevent measurements in both the crown and cement-enamel junction, but rarely so at the level of the root [56]. In the case of burned teeth, crowns present another problem. They tend to preserve very poorly. When subjected to high temperatures, fractures occur on dental crowns due to the increase of pressure, caused by water evaporation, between the enamel and the dentine $[11,21,59,60]$. Dental roots have no enamel and contain less water thus leading in turn to less pressure and less fractures [11, 21, 52, 59, 60, 85]. Recently, Hillson et al. [56] proposed alternative standards measurements based on the CEJ to overcome such problems and Tuttösí and Cardoso [61] demonstrated their potential for sex estimation. These, along with those from the root, could prove useful for sex estimation of burned skeletal remains but research is needed to assess this.

The problem of using odontometry on burned teeth is that they may have been affected by heat-induced 
dimensional changes which can be particularly large in high temperature burnings [4, 21, 62]. That is why this investigation focused not only on burned teeth but also on their pre-burned versions. Although some of the standard measurements used in this research have been investigated previously, the true value for sex estimation of the new standard measurements here proposed had to be assessed prior to the experimental burning. In addition, heat-induced dimensional changes were documented to determine how impeditive of sex estimation they really are. As for heat-induced warping, apparently this is not a common problem in teeth according to Sandholzer et al. [63], contrary to what has been documented for bones [4]. Therefore, warping does not seem to interfere with odontometric analysis of burned teeth.

In some contexts, large assemblages of burned skeletal remains from multiple individuals need to be analysed. For example, that is the case involving mass disasters. In such situations, it is possible that the remains have been subjected to similar heat conditions. It would then be useful to evaluate the potential of sample-specific methods for sex estimation in these situations. Therefore, a secondary objective was to test this kind of procedure in a sample burned at similar conditions. If proven useful, sample-specific methods may be one practical way of solving the problem that heat-induced dimensional changes pose to metric sex estimation. Compared with the other three approaches, the sample-specific one has the advantage of automatically taking into consideration the extent of heat-induced dimensional changes affecting the sample instead of trying to estimate it based on references obtained from unrelated researches [72]. It does so because it generates methods internally consistent with the sexual dimorphism present in the sample [61].

Measurements from the CEJ and the root have been investigated in this paper. One disadvantage of using these features is that they are harder to identify due to the frequent lack of the crown. However, if demonstrated to be reliable, an approach based on those measurements would turn out in several important benefits. First, dental roots resist better to high temperatures than dental crowns [19, 52, 64] so they are more often recovered in good condition. Second, root measurements are less often affected by wear. Third, CEJ and root measurements are allegedly more objective than crown measurements and other non-metric techniques based on non-dental features of the skeleton [37, 52]. Four, dental sex estimation can be applied to non-adult individuals since several teeth are formed before adulthood [52, 65, 66]. Given all these benefits, the approach here proposed will expectantly contribute for the sex estimation of skeletal remains, especially those that are very incomplete, fragmented and affected by heatinduced changes.

The objective of this paper is to evaluate the reliability of dental standard measurements, some already established and others here proposed, for sex estimation of burned human skeletal remains. For that purpose, the sexual dimorphism and the heat-induced changes present in a sample of experimentally burned teeth from individuals of known sex and age was investigated to better assess their potential for sex estimation. Ultimately, the goal was to detect if any tooth dimension was more successful at withstanding heat-induced dimensional changes. 


\section{Material and Methods}

Sixty teeth, 20 permanent lower second pre-molars from each sex and 10 permanent upper central incisors and 10 permanent lower first molars, extracted in dental offices were donated to the University of Coimbra after informed consent of the patients (Ref. 108-CE-2014). Sex, age and nationality of the individuals were known. Additionally, the cause of dental extraction and associated oral pathologies were recorded. Teeth were then cleaned and removed from soft tissues. Sample selection focused on (1) the most represented tooth-types which were the upper central incisors, the upper first molars and the second lower pre-molars (in the specific case of the sex estimation investigation, the second lower pre-molar was used due to its previously reported high level of sexual dimorphism [52, 67, 77]; the other two kinds of teeth were used to investigate heat-induced dimensional changes); (2) tooth-types with small variability (as a result, the third molars were discarded [14, 39, 47, 68, 69]); and (3) teeth less prone to restorative processes, abrasion, caries and other oral pathologies. Calculus was scraped from the tooth surface when it prevented measuring which was performed by using a Mitutoyo Digimatic caliper (0.01 mm precision) both previously and after the experimental burning. The latter was preceded by the tooth consolidation with the acrylic preservative PRIMAL ${ }^{\mathrm{TM}}$ SF-016 ER to enhance its conservation and avoid damage. Teeth were coated with only a very thin and imperceptible layer of preservative to avoid influencing subsequent measurements. Finally, the perimeter was measured using a thread.

Heat-induced dimensional changes were documented on three sub-samples by comparing the postburning dimensions with the pre-burning ones: group 1 was composed of 10 permanent upper central incisors (UCI) from individuals with ages between 43 and 83 years old; group 2 was composed of 10 permanent upper first molars (UM1) from individuals aged from 26 to 71 years old. The two samples were not comprised of the same tooth type because none had a large enough number. The maximum temperature burning of the UCI sample was $400^{\circ} \mathrm{C}$ and took 90 minutes to attain. As for the UM1, the maximum temperature was $700^{\circ} \mathrm{C}$ and took 210 minutes to attain. In these burnings, the mean temperature increment was $4.4^{\circ} \mathrm{C}$ and $3.3^{\circ} \mathrm{C}$ per minute, respectively. Then, the electric muffle Barracha K-3 three-phase 14A was switched off and the teeth were allowed to cool down to room temperature. An electric muffle was used for the burnings and therefore does not replicate all burning conditions affecting human remains examined by forensic anthropologists. Nonetheless, such devices are very commonly used for ceramics related work and may eventually be used to destroy a body. In addition, electric cremators are also common in crematoria and malpractice can also be the focus of forensic investigations. More importantly, the type of burning equipment is less important than the intensity of burning since it is the latter that causes variable changes to skeletal remains and does it in a predictable sequence regardless of the source of heating $[88,89]$. The burning temperature and duration were therefore selected to simulate real burning scenarios $[4,21,86]$ disregarding the teeth position on the alveoli, fire direction, use of accelerants, the effect that fast temperature increments may have on the burning process and the possible effect of the presence of soft tissues [10, 19, 63, 87]. Regarding the latter however, it is the changes in the crystal structure that are mainly involved in bone and teeth alterations in size; and those are a result of heating and not of soft tissue presence per se. The only known participation of soft tissue in heat-induced dimensional changes regards its insulation and protective function that may delay or prevent teeth 
exposure to heat. Once exposure occurs after soft tissue pyrolysis, the normal sequence of heat-induced degradation takes place nonetheless.

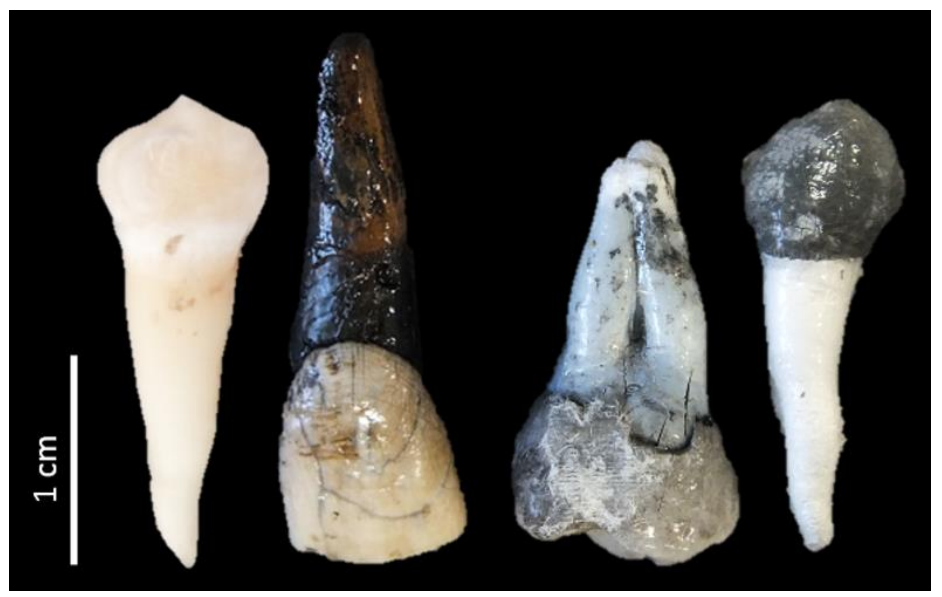

Figure 1. Progressive color changes induced by heat. From left to right: mandibular second premolar unburned; maxillary right central incisor burned to $400^{\circ} \mathrm{C}$; maxillary first molar right burned to $700^{\circ} \mathrm{C}$ and mandibular second premolar right burned to $900^{\circ} \mathrm{C}$.

Finally, group 3 was used for the investigation of sexual dimorphism and sex estimation. The sample was composed of 40 permanent lower second pre-molars (LPM2), belonging to 20 males and 20 females with ages ranging from 15 to 91 years old. The LPM2 was chosen for the analysis of sexual dimorphism and potential for sex estimation because they constituted a large enough sample size for statistical testing. Also, it was the tooth presenting fewer fillings, less wear and fewer oral pathologies. The LPM2 is not very variable, contrary to other teeth such as the molars [47, 67-70]. A test carried out on the Collection of Identified Skeletons of the University of Coimbra (CIS) was carried out to assess if the LPM2 presents significant bilateral asymmetry in the standard measurements taken here into consideration, as described in Table 1. This test was carried out to find out if left and right LPM2 could be combined into a single and therefore enlarged sample. The LPM2 sample was then experimentally burned in an electric muffle from room temperature to a maximum temperature of $900^{\circ} \mathrm{C}$ and the burning lasted 240 minutes $\left(4.3^{\circ}\right.$ $\mathrm{C} /$ minute). In this pilot study, tooth preservation was essential to objectively assess heat-induced changes and to evaluate odontometric potential for sex estimation. As expected, the use of slow temperature increments minimized tooth degradation. An example of the optimal preservation of teeth burned at each temperature category is presented in Figure 1. Teeth recovered from other burning contexts may present various preservation states and often are in poorer conditions than the ones obtained in this research. However, degradation tends to be more substantial in the crown and dental roots are often found intact thus justifying our experimental approach. 
Table 1 - Description of standard measurements investigated in this research.

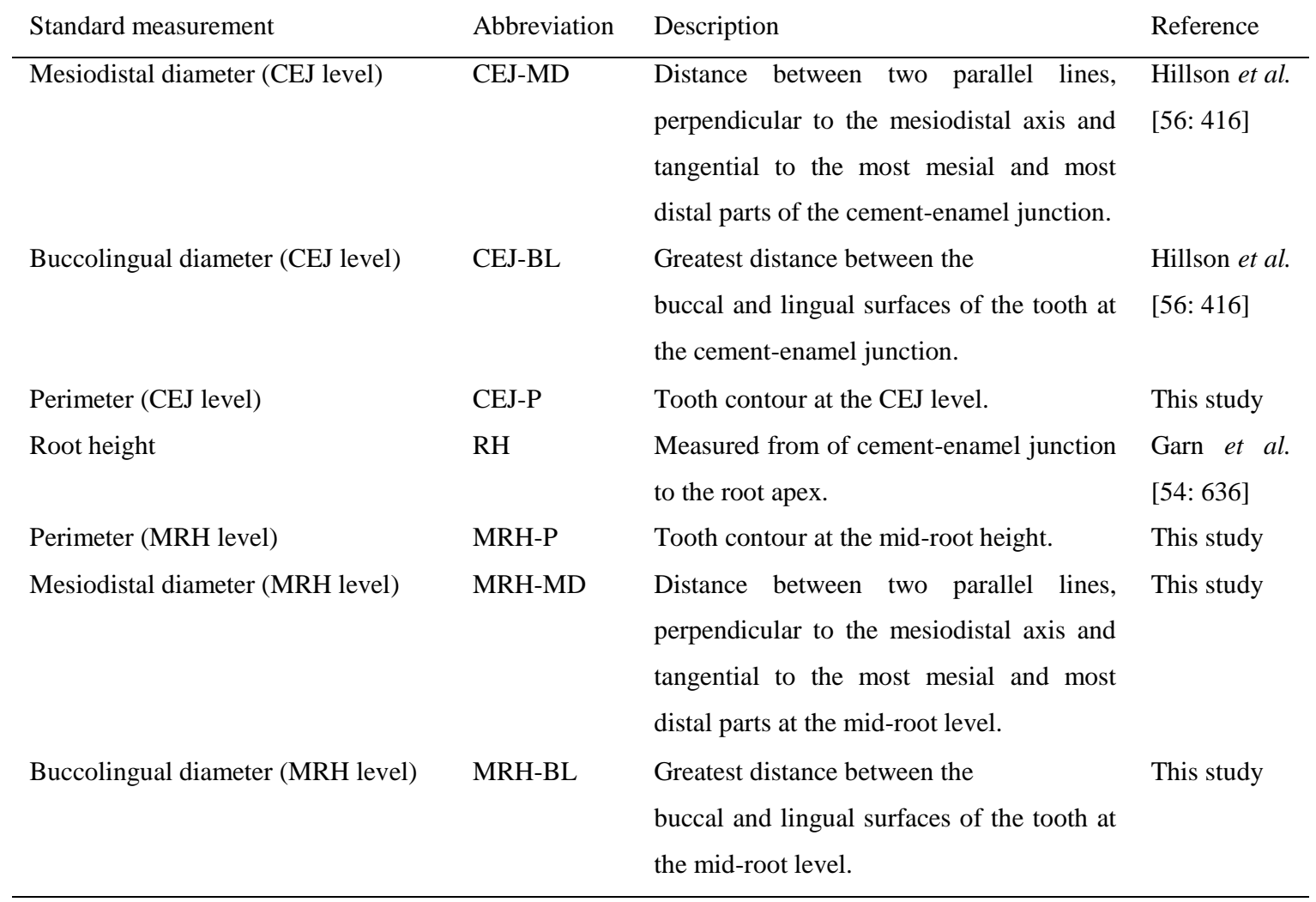

Intra- and inter-observer variation was assessed through the calculation of the technical error of measurement [71]. The two sets of measurements for the intra-observer variation were taken one month apart from each other. A second observer, experienced in odontometric analysis measured the same subsample in order to test the inter-observer error. The subsequent metric analysis was performed both previously and after the experimental burnings. Besides using each standard measurement, combined features in the form of summed measurements were also used.

To determine if standard measurements were sexually dimorphic, sexual differences were statistically assessed either with parametric (independent samples t-test) and non-parametric tests (Mann-Whitney) depending on whether the parametric assumptions were met or not. No testing of sex estimation based on the application of sex discriminating sectioning points was carried out on an independent sample because the amount of available teeth was not large enough to allow it. Also, that was not the main objective of this research since we intended to assess the potential of sample-specific sex estimation following the recommendations of Albanese et al. [72] and Cardoso [37]. All statistical tests were carried out by using the SPSS software, version 17.0 (SPSS Inc., Chicago, IL).

Sample-specific sex estimation was attempted since the sample, for most measurements, met the three assumptions proposed by Albanese et al. [72]. The sample was larger than 40 individuals, was composed of both sexes with a sex ratio lower than 1.5:1 and the distribution of odontometric values was approximately normal. However, in the latter case, that was not so for three isolated measurements (buccolingual diameter at the CEJ level; perimeter and the buccolingual diameter at the MRH level). 
Nonetheless, we chose to apply the sample-specific method based on these measurements because it was known for sure that the sex-ratio was balanced. Then, the mean value of each standard measurement was used as a sectioning point to classify individuals according to sex. Values above this point were classified as males while the remaining ones were classified as females. As a precautionary measure, individuals with dimensions contained by the $99 \%$ confidence interval of the mean, built according to its standard error, were classified as undetermined.

Results

The technical error of measurement (TEM) showed good replicability of all measurements. In the case of the intra-observer variation, the absolute TEM ranged from 0.02 to $0.22 \mathrm{~mm}$ and the relative TEM ranged from 0.40 to $5.67 \%[18,52]$. The coefficient of reliability ranged from 0.990 to 0.999 , indicating that only a small portion of the variation was the result of measurement errors.

Statistical tests for paired samples (t-test and Wilcoxon) found no significant differences between the left and right LPM2 in all standards measurements. Significance varied from 0.053 to 0.572 (Table 2). Even in the case of the former value, which refers to the MRH-MD, the mean values from both sides were only $0.05 \mathrm{~mm}$ different so combined samples were used also in this case.

Table 3 gives the mean percentage of heat-induced dimensional change per temperature category. In general, it was larger for teeth burned at higher temperatures. Surprisingly, the CEJ-BL and CEJ-P of the $900^{\circ} \mathrm{C}$ sample showed less mean shrinkage than the one observed in the samples burned at lower temperatures. This can be explained by heat-induced increase which was observed mostly in teeth burned at $900^{\circ} \mathrm{C}$ thus affecting the overall mean dimensional change of every standard measurement. Regrettably, all dimensions were considerably affected by dimensional changes, even at $400^{\circ} \mathrm{C}$ although only shrinkage was a major concern in this case. The same can be said for the sample burned at $700^{\circ} \mathrm{C}$ although some cases of relatively small heat-induced increase were observed. At $900^{\circ} \mathrm{C}$, results were more variable according to each standard measurement. All presented cases of large maximum shrinkage. The CEJ-P was the one presenting the smallest maximum value. As for heat-induced increase, only the R$\mathrm{H}$ and the MRH-P presented small maximum values. In summary, it can be said that, as expected, heatinduced dimensional changes were especially problematic in the sample burned at $900^{\circ} \mathrm{C}$. Interestingly, heat-induced dimensional changes affected males and females differently. As a result, mean sex differences in some measurements (CEJ-BL, CEJ-P, RH, MRH-P and MRH-BL) were actually enlarged due to this, especially in the case of the sample burned at $900^{\circ} \mathrm{C}$.

Table 4 discriminates the amount of teeth presenting shrinkage and increase per each dimension as well as the amount of teeth not presenting any dimensional change at $900^{\circ} \mathrm{C}$. The distribution between the three categories was quite variable. More cases of heat-induced increase were found for the CEJ dimensions. In particular, the amount of teeth presenting it at the CEJ-P was very similar to the amount of teeth presenting shrinkage. In the case of the other dimensions at the root level, only a very small minority $(4.0 \%)$ presented heat-induced increase. 
Significant mean sex differences were found in all isolated measurements and in all combined measurements in both pre-burned and post-burned teeth (Tables 5 and 6). The pre-burning most significant sex differences were the ones observed on the isolated MRH-MD $(p=.006)$ and on the CEJML and CEJ-BL combined measurements $(p=.004)$. The post-burning most significant sex differences were found on the isolated RH $(p=.006)$ and on four combined measurements $(p=.001): 1)$ CEJ-MD + CEJ-P + MRH-BL; 2) CEJ-BL + CEJ-MD; 3) CEJ-BL + CEJ-MD + CEJ-P; and 4) CEJ-BL + CEJ-P. Therefore, in general, the combined measurements provided better results.

Tables 7 and 8 give the results for sex classification based on the sample-specific mean value which was used as sectioning point. Previously to burning, none of the measurements provided very successful sex classifications since these should be as close to $100.0 \%$ as possible. A somewhat better result was obtained in the case of the combined measurements, although still unsatisfactory since sex classifications close to $100.0 \%$ for both males and females were never obtained. After burning, results were slightly better. Among the isolated measurements, the CEJ-P was successfully used in $81.8 \%$ of the cases in both males and females. As for the combined measurements, the best combination was the one formed by CEJMD + CEJ-BL with successful male allocation of $88.9 \%$ and successful female allocation of $83.3 \%$. Although with reasonable results, most of the other combinations did not provide successful sex classifications higher than $80.0 \%$ in both sexes.

Table 2 - Statistics for measurements (Meas.) of left and right permanent lower second pre-molars (LPM2). Measurements are given in $\mathrm{mm}$.

$\begin{array}{lll}\text { Meas. } & \text { LPM2 (left) LPM2 (right) }\end{array}$

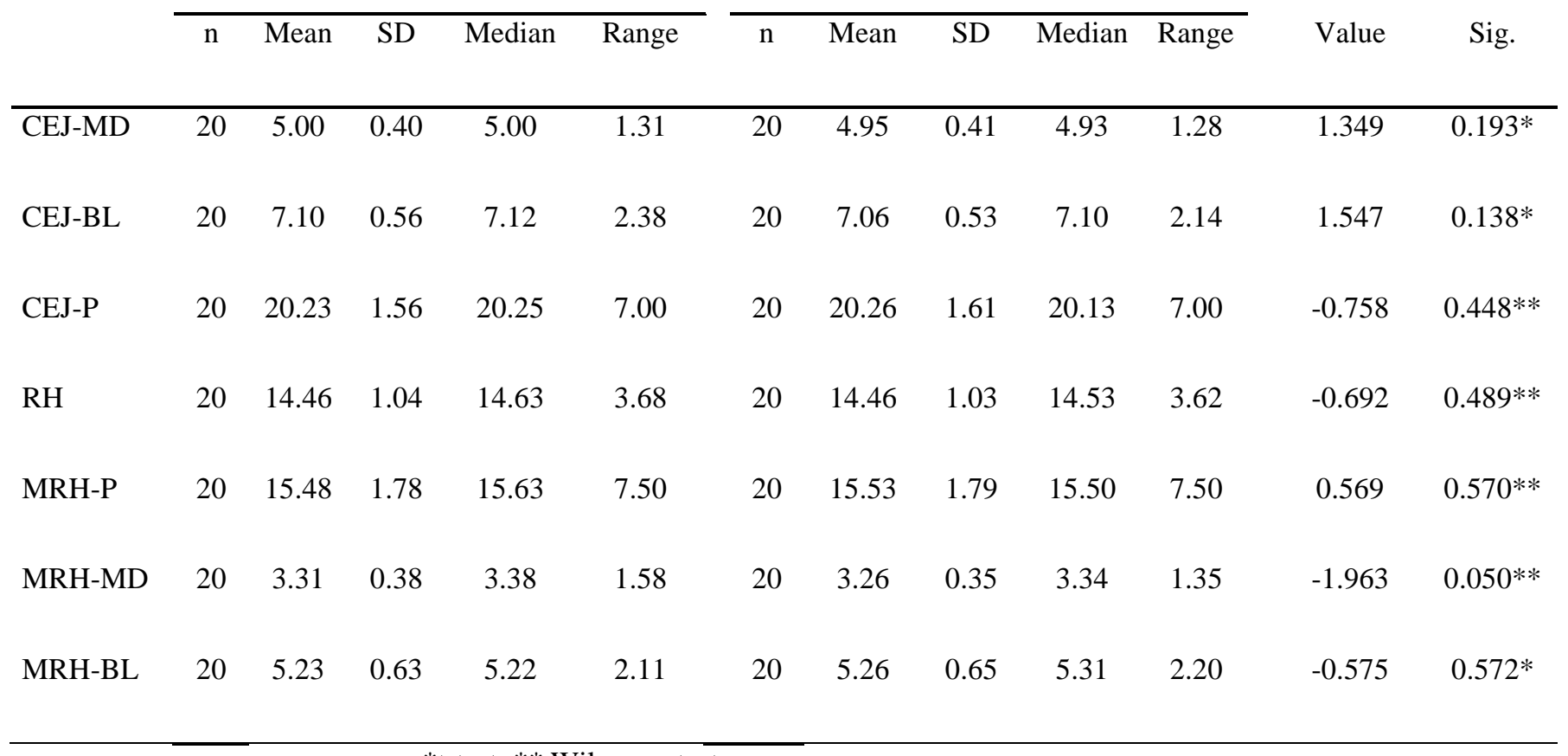

*t-test; ** Wilcoxon test 
Table 3 - Descriptive statistics for heat-induced dimensional changes in all measurements (Meas.) according to each maximum temperature category. The mean (M), the standard deviation (SD), the minimum (Min) and maximum (Max) values are presented for each sex and for the pooled results (P). Values are given in percentage. Negative values refer to shrinkage and positive values refer to increase.

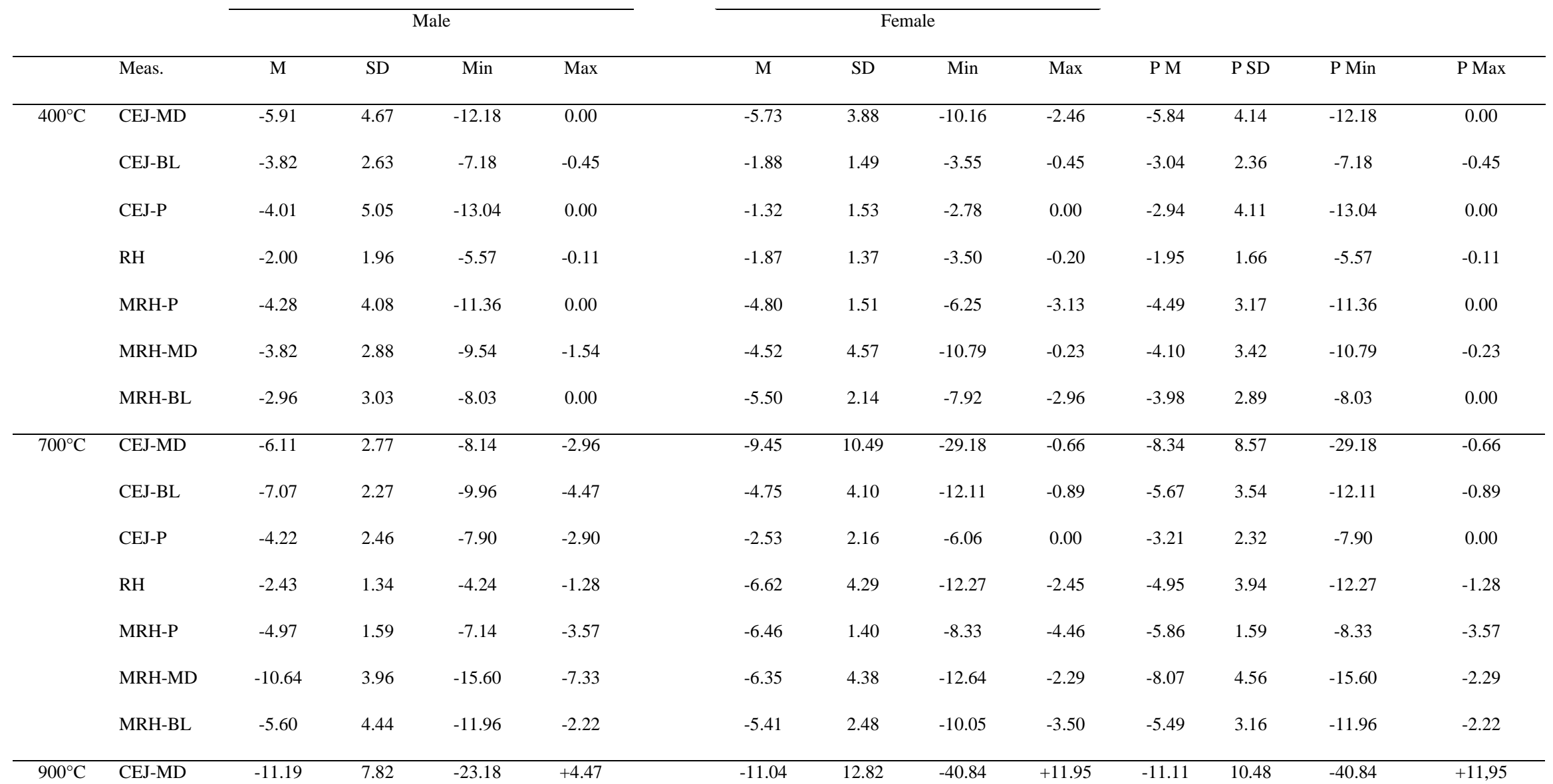




\begin{tabular}{|c|c|c|c|c|c|c|c|c|c|c|c|c|}
\hline CEJ-BL & -2.81 & 10.14 & -13.99 & +27.81 & -5.05 & 5.93 & -15.63 & +9.97 & -3.90 & 8.33 & -15.63 & $+27,81$ \\
\hline CEJ-P & -1.20 & 8.28 & -11.58 & +18.75 & -1.37 & 6.15 & -14.13 & +9.09 & -1.28 & 7.20 & -14.13 & $+18,75$ \\
\hline RH & -10.09 & 3.24 & -19.77 & -5.98 & -12.53 & 5.97 & -23.43 & +3.25 & -11.31 & 4.90 & -23.43 & $+3,25$ \\
\hline MRH-P & -8.87 & 6.28 & -23.19 & 0.00 & -11.28 & 7.29 & -24.64 & +3.57 & -10.07 & 6.83 & -24.64 & $+3,57$ \\
\hline MRH-MD & -13.05 & 9.88 & -35.00 & +11.25 & -12.09 & 5.68 & -18.36 & +1.31 & -12.57 & 7.97 & -35.00 & $+11,25$ \\
\hline MRH-BL & -9.60 & 12.99 & -27.02 & +40.43 & -10.45 & 7.70 & -19.87 & +17.13 & -10.02 & 10.55 & -27.02 & $+40,43$ \\
\hline
\end{tabular}

Table 4 - Relative dimensional changes at each standard measurement (Meas.) of teeth burned at $900^{\circ} \mathrm{C}$. The mean, the standard deviation (SD), the minimum (Min) and maximum (Max) values are presented for each dimension. Values are given in percentage. Negative values refer to shrinkage and positive values refer to increase.

\begin{tabular}{|c|c|c|c|c|c|c|}
\hline Meas. & Dimensional Change & $\mathrm{n}$ & Mean & $\mathrm{SD}$ & Max. & Min. \\
\hline \multirow[t]{3}{*}{ CEJ-MD } & Shrinkage & 33 & -14.60 & 7.681 & -40.84 & -0.24 \\
\hline & Increase & 7 & +5.31 & 4.158 & +0.99 & +11.95 \\
\hline & No change & - & - & - & - & - \\
\hline \multirow[t]{3}{*}{ CEJ-BL } & Shrinkage & 33 & -6.73 & 3.881 & -15.63 & -0.44 \\
\hline & Increase & 6 & +11.66 & 9.367 & +1.16 & +27.81 \\
\hline & No change & - & - & - & - & - \\
\hline \multirow[t]{3}{*}{ CEJ-P } & Shrinkage & 20 & -6.92 & 3.832 & -14.13 & -1.25 \\
\hline & Increase & 16 & +5.45 & 4.997 & +1.19 & +18.75 \\
\hline & No change & 4 & - & - & - & - \\
\hline $\mathrm{R}-\mathrm{H}$ & Shrinkage & 39 & 11.68 & 4.35 & -23.43 & 5.98 \\
\hline
\end{tabular}




\begin{tabular}{|c|c|c|c|c|c|c|}
\hline & Increase & 1 & - & - & - & - \\
\hline & No change & - & - & - & - & - \\
\hline \multirow[t]{3}{*}{ MRH-MD } & Shrinkage & 38 & -13.56 & 6.738 & -35.00 & -1.80 \\
\hline & Increase & 2 & +6.28 & 7.028 & +1.31 & +11.25 \\
\hline & No change & - & - & - & - & - \\
\hline \multirow[t]{3}{*}{ MRH-BL } & Shrinkage & 38 & -12.07 & 4.926 & -27.02 & -5.06 \\
\hline & Increase & 2 & +28.78 & 16.48 & +17.13 & +40.43 \\
\hline & No change & - & - & - & - & - \\
\hline \multirow[t]{3}{*}{ MRH-P } & Shrinkage & 36 & -11.29 & 6.031 & -24.64 & -1.78 \\
\hline & Increase & 1 & 1 & - & - & - \\
\hline & No change & 3 & - & - & - & - \\
\hline
\end{tabular}

Table 5 - Descriptive and inferential statistics for sex differences in all isolated and combined measurements of the unburned teeth. Measurements (Meas.) given in mm.

\begin{tabular}{|c|c|c|c|c|c|c|c|c|c|c|c|c|c|}
\hline \multirow[b]{2}{*}{ Meas. } & \multicolumn{5}{|c|}{ Female } & \multicolumn{5}{|c|}{ Male } & \multirow[b]{2}{*}{ Value } & \multirow[b]{2}{*}{ Sig. } & \multirow[b]{2}{*}{ d } \\
\hline & $\mathrm{n}$ & Mean & $\mathrm{SD}$ & Median & Range & $\mathrm{n}$ & Mean & SD & Median & Range & & & \\
\hline CEJ-MD & 20 & 4.93 & 0.49 & 5.02 & 1.60 & 20 & 5.34 & 0.61 & 5.14 & 2.09 & $2.34^{*}$ & 0.025 & 0.74 \\
\hline CEJ-BL & 19 & 6.83 & 0.65 & 6.73 & 2.90 & 20 & 7.44 & 0.97 & 7.14 & 3.67 & $118.00 * *$ & 0.043 & 0.74 \\
\hline CEJ-P & 20 & 19.13 & 1.75 & 19.00 & 7.00 & 20 & 20.59 & 2.12 & 20.25 & 9.00 & $2.38 *$ & 0.023 & 0.75 \\
\hline RH & 20 & 14.35 & 1.69 & 14.38 & 5.82 & 20 & 15.64 & 1.90 & 16.07 & 6.84 & $2.26^{*}$ & 0.030 & 0.71 \\
\hline MRH-P & 20 & 15.59 & 1.43 & 15.75 & 5.00 & 20 & 17.05 & 2.25 & 16.88 & 9.00 & $119.50 * *$ & 0.029 & 0.78 \\
\hline
\end{tabular}




\begin{tabular}{|c|c|c|c|c|c|c|c|c|c|c|c|c|c|}
\hline MRH-MD & 20 & 3.33 & 0.39 & 3.34 & 1.30 & 20 & 3.69 & 0.37 & 3.76 & 1.18 & $100.50^{* *}$ & 0.007 & 0.95 \\
\hline MRH-BL & 20 & 5.08 & 0.68 & 5.17 & 2.42 & 20 & 5.87 & 1.17 & 5.55 & 4.73 & $122.00 * *$ & 0.035 & 0.82 \\
\hline $\begin{array}{l}\text { CEJ-MD+CEJ-P+MR- } \\
\text { BL }\end{array}$ & 20 & 29.14 & 2.51 & 29.36 & 9.50 & 20 & 31.8 & 3.35 & 31.04 & 14.26 & $-2.83^{*}$ & 0.007 & 0.90 \\
\hline CEJ-BL + CEJ-MD & 19 & 11.42 & 1.72 & 11.46 & 8.08 & 20 & 12.78 & 1.34 & 12.70 & 5.07 & $94.00^{* *}$ & 0.004 & 0.88 \\
\hline $\begin{array}{l}\text { CEJ-BL + CEJ-MD + } \\
\text { CEJ-P }\end{array}$ & 20 & 30.54 & 2.79 & 30.73 & 11.08 & 20 & 33.37 & 3.23 & 32.37 & 13.89 & $-2.96^{*}$ & 0.005 & 0.94 \\
\hline CEJ-BL + CEJ-P & 20 & 25.61 & 2.62 & 26.08 & 11.46 & 20 & 28.02 & 2.95 & 27.21 & 12.67 & $-2.74 *$ & 0.009 & 0.87 \\
\hline CEJ-MD + CEJ-P & 20 & 24.06 & 2.01 & 24.19 & 7.37 & 20 & 25.93 & 2.40 & 25.37 & 10.22 & $-2.68 *$ & 0.011 & 0.85 \\
\hline
\end{tabular}

*t-test; ** Mann-Whitney test

Table 6 - Descriptive and inferential statistics for sex differences in all isolated and combined measurements of the burned teeth. Measurements (Meas.) given in mm.

\begin{tabular}{|c|c|c|c|c|c|c|c|c|c|c|c|c|c|}
\hline \multirow[b]{2}{*}{ Meas. } & \multicolumn{5}{|c|}{ Female } & \multicolumn{5}{|c|}{ Male } & \multirow[b]{2}{*}{ Value } & \multirow[b]{2}{*}{ Sig. } & \multirow[b]{2}{*}{$\mathrm{d}$} \\
\hline & $\mathrm{n}$ & Mean & SD & Median & Range & $\mathrm{n}$ & Mean & SD & Median & Range & & & \\
\hline CEJ-MD & 20 & 4.35 & 0.46 & 4.43 & 1.97 & 20 & 4.74 & 0.61 & 4.62 & 2.04 & $2.26^{*}$ & 0.029 & 0.72 \\
\hline CEJ-BL & 19 & 6.48 & 0.69 & 6.32 & 2.82 & 20 & 7.20 & 1.00 & 7.15 & 3.53 & $2.48 *$ & 0.018 & 0.85 \\
\hline CEJ-P & 20 & 18.80 & 1.37 & 19.00 & 5.50 & 20 & 20.24 & 1.68 & 20.00 & 7.50 & $107.00 * *$ & 0.012 & 0.94 \\
\hline RH & 20 & 12.54 & 1.59 & 12.77 & 6.71 & 20 & 14.05 & 1.70 & 14.34 & 5.70 & $2.88 *$ & 0.006 & 0.91 \\
\hline
\end{tabular}




\begin{tabular}{|c|c|c|c|c|c|c|c|c|c|c|c|c|c|}
\hline MRH-P & 20 & 13.80 & 1.39 & 14.25 & 4.75 & 20 & 15.51 & 2.17 & 15.00 & 8.50 & $113.00 * *$ & 0.018 & 0.94 \\
\hline MRH-MD & 20 & 2.93 & 0.37 & 3.02 & 1.26 & 20 & 3.19 & 0.34 & 3.26 & 1.15 & $2.38 *$ & 0.022 & 0.75 \\
\hline MRH-BL & 20 & 4.53 & 0.52 & 4.54 & 2.07 & 20 & 5.25 & 0.98 & 5.16 & 3.98 & $107.00 * *$ & 0.012 & 0.92 \\
\hline CEJ-MD+CEJ-P+MR-BL & 20 & 29.48 & 2.54 & 29.40 & 8.69 & 20 & 32.69 & 3.03 & 32.45 & 13.45 & $77.00 * *$ & 0.001 & 1.15 \\
\hline CEJ-BL + CEJ-MD & 19 & 10.50 & 1.50 & 10.67 & 7.74 & 20 & 11.94 & 1.35 & 11.66 & 4.67 & $83.00 * *$ & 0.002 & 1.01 \\
\hline $\begin{array}{l}\text { CEJ-BL + CEJ-MD + CEJ- } \\
P\end{array}$ & 20 & 29.30 & 2.16 & 29.49 & 8.07 & 20 & 32.17 & 2.68 & 32.08 & 12.17 & $77.00 * *$ & 0.001 & 1.18 \\
\hline CEJ-BL + CEJ-P & 20 & 24.95 & 2.21 & 25.00 & 8.60 & 20 & 27.44 & 2.40 & 27.42 & 11.03 & $84.00 * *$ & 0.002 & 1.08 \\
\hline CEJ-MD + CEJ-P & 20 & 23.15 & 1.46 & 23.16 & 6.03 & 20 & 24.97 & 1.95 & 25.00 & 8.64 & $86.00 * *$ & 0.002 & 1.06 \\
\hline
\end{tabular}

*t-test; ** Mann-Whitney test

Table 7 - Correct sex classification (CC) based on the 99\% confidence intervals (given in mm) of the mean of the unburned isolated and combined standard measurements (Meas.).

\begin{tabular}{|c|c|c|c|c|c|c|c|c|c|c|c|c|}
\hline \multirow[b]{2}{*}{ Meas. } & \multirow[b]{2}{*}{$\mathrm{N}$} & \multirow[b]{2}{*}{ Mean } & \multirow[b]{2}{*}{ Lower bound } & \multirow[b]{2}{*}{ Upper bound } & \multicolumn{2}{|r|}{ Male } & \multicolumn{2}{|r|}{ Female } & \multirow[b]{2}{*}{$? \mathrm{n}$} & \multirow[b]{2}{*}{ ?Proportion } & \multirow[b]{2}{*}{ SP n } & \multirow[b]{2}{*}{$\mathrm{SP}(\mathrm{n})$} \\
\hline & & & & & $\mathrm{n}$ & $\mathrm{CC}(\mathrm{n})$ & $\mathrm{n}$ & $\mathrm{CC}(\mathrm{n})$ & & & & \\
\hline CEJ-MD & 40 & 5.14 & 4.90 & 5.38 & 11 & $63.64 \%(7)$ & 11 & $72.73 \%(8)$ & 18 & 45.00 & 22 & $68.18 \%$ \\
\hline CEJ-BL & 39 & 7.14 & 6.78 & 7.50 & 9 & $77.78 \%(7)$ & 17 & $64.71 \%(11)$ & 13 & 33.33 & 26 & $69.23 \%(18)$ \\
\hline CEJ-P & 40 & 19.86 & 19.02 & 20.70 & 10 & $80.00 \%$ (8) & 17 & $64.71 \%(11)$ & 13 & 32.50 & 27 & $70.37 \%$ (19) \\
\hline R-H & 40 & 16.32 & 15.50 & 17.14 & 6 & $66.67 \%(4)$ & 24 & $66.67 \%(16)$ & 10 & 25.00 & 30 & $66.67 \%(20)$ \\
\hline
\end{tabular}




\begin{tabular}{|c|c|c|c|c|c|c|c|c|c|c|c|c|}
\hline MRH-P & 40 & 14.99 & 14.22 & 15.76 & 26 & $61.54 \%(16)$ & 3 & $100.00 \%$ & 11 & 27.50 & 29 & $65.52 \%(19)$ \\
\hline MRH-MD & 40 & 3.51 & 3.34 & 3.68 & 15 & $80.00 \%(12)$ & 16 & $68.75 \%(11)$ & 9 & 22.50 & 31 & $74.19 \%(23)$ \\
\hline MRH-BL & 40 & 5.48 & 5.06 & 5.89 & 10 & $80.00 \%(8)$ & 13 & $61.54 \%(8)$ & 17 & 42.50 & 23 & $69.57 \%(16)$ \\
\hline $\begin{array}{l}\text { CEJ-MD+CEJ-P+MRH- } \\
\text { BL }\end{array}$ & 40 & 30.47 & 29.16 & 31.78 & 10 & $80.00 \%(8)$ & 13 & $76.92 \%(10)$ & 17 & $42.50 \%$ & 23 & $78.26 \%(18)$ \\
\hline CEJ-BL + CEJ-MD & 40 & 12.10 & 11.42 & 12.78 & 14 & $71.43 \%(10)$ & 11 & $81.82 \%(9)$ & 15 & $37.50 \%$ & 25 & $76.00 \%$ (19) \\
\hline $\begin{array}{l}\text { CEJ-BL + CEJ-MD + } \\
\text { CEJ-P }\end{array}$ & 40 & 31.95 & 30.60 & 33.30 & 11 & $81.82 \%(9)$ & 13 & $76.92 \%(10)$ & 16 & $40.00 \%$ & 24 & $79.17 \%$ (19) \\
\hline CEJ-BL + CEJ-P & 40 & 26.82 & 25.59 & 28.05 & 10 & $80.00 \%(8)$ & 12 & $75.00 \%(9)$ & 18 & $45.00 \%$ & 22 & $77.27 \%(17)$ \\
\hline CEJ-MD + CEJ-P & 40 & 24.99 & 24.02 & 25.96 & 12 & $75.00 \%(9)$ & 14 & $71.43 \%(10)$ & 14 & $35.00 \%$ & 26 & $73.08 \%$ \\
\hline
\end{tabular}

Key: ? = undetermined sex; SP = sex-pooled.

Table 8 - Correct sex classification (CC) based on the $99 \%$ confidence intervals (given in mm) of the mean of the burned isolated and combined standard measurements (Meas.).

\begin{tabular}{|c|c|c|c|c|c|c|c|c|c|c|c|c|}
\hline \multirow[b]{2}{*}{ Meas. } & \multirow[b]{2}{*}{$\mathrm{N}$} & \multirow[b]{2}{*}{ Mean } & \multirow[b]{2}{*}{ Lower bound } & \multirow[b]{2}{*}{ Upper bound } & \multicolumn{2}{|r|}{ Male } & \multicolumn{2}{|c|}{ Female } & \multirow[b]{2}{*}{$? \mathrm{n}$} & \multirow[b]{2}{*}{ ?Proportion } & \multirow[b]{2}{*}{ SP n } & \multirow[b]{2}{*}{$\mathrm{SP}(\mathrm{n})$} \\
\hline & & & & & $\mathrm{n}$ & $\mathrm{CC}(\mathrm{n})$ & $\mathrm{n}$ & $\mathrm{CC}(\mathrm{n})$ & & & & \\
\hline CEJ-MD & 40 & 4.54 & 4.31 & 4.77 & 11 & $72.73 \%(8)$ & 14 & $57.14 \%(8)$ & 15 & 37.50 & 25 & $64.00 \%(16)$ \\
\hline CEJ-BL & 39 & 6.85 & 6.47 & 7.23 & 10 & $90.00 \%(9)$ & 17 & $64.71 \%(11)$ & 11 & 28.21 & 27 & $74.07 \%(20)$ \\
\hline CEJ-P & 40 & 19.52 & 18.83 & 20.20 & 11 & $81.82 \%(9)$ & 11 & $81.82 \%(9)$ & 18 & 45.00 & 22 & $81.82 \%(18)$ \\
\hline
\end{tabular}




\begin{tabular}{|c|c|c|c|c|c|c|c|c|c|c|c|c|}
\hline R-H & 40 & 14.66 & 13.84 & 15.47 & 4 & $75.00 \%(3)$ & 25 & $68.00 \%(17)$ & 11 & 27.50 & 29 & $68.97 \%(20)$ \\
\hline MRH-P & 40 & 13.29 & 12.56 & 14.03 & 23 & $56.52 \%(13)$ & 5 & $80.00 \%(4)$ & 12 & 30.00 & 28 & $60.71 \%(17)$ \\
\hline MRH-MD & 40 & 3.06 & 2.91 & 3.21 & 18 & $66.67 \%(12)$ & 15 & $60.00 \%(9)$ & 7 & 17.50 & 33 & $63.64 \%(21)$ \\
\hline MRH-BL & 40 & 4.89 & 4.54 & 5.24 & 9 & $100.00 \%(9)$ & 14 & $71.43 \%(10)$ & 17 & 42.50 & 23 & $82.61 \%(19)$ \\
\hline CEJ-MD+CEJ-P+MRH-BL & 40 & 31.08 & 29.78 & 32.39 & 14 & $78.57 \%(11)$ & 15 & $80.00 \%(12)$ & 11 & $27.50 \%$ & 29 & $79.31 \%(23)$ \\
\hline CEJ-BL + CEJ-MD & 40 & 11.22 & 10.57 & 11.87 & 9 & $88.89 \%(8)$ & 12 & $83.33 \%(10)$ & 19 & $47.50 \%$ & 21 & $85.71 \%(18)$ \\
\hline $\begin{array}{l}\text { CEJ-BL + CEJ-MD + CEJ- } \\
P\end{array}$ & 40 & 30.74 & 29.59 & 31.88 & 12 & $83.33 \%(10)$ & 14 & $78.57 \%(11)$ & 14 & $35.00 \%$ & 26 & $80.77 \%(21)$ \\
\hline CEJ-BL + CEJ-P & 40 & 26.20 & 25.13 & 27.26 & 13 & $76.92 \%(10)$ & 14 & $78.57 \%(11)$ & 13 & $32.50 \%$ & 27 & $77.78 \%(21)$ \\
\hline CEJ-MD + CEJ-P & 40 & 24.06 & 23.27 & 24.85 & 12 & $91.67 \%(11)$ & 14 & $71.43 \%(10)$ & 14 & $35.00 \%$ & 26 & $80.77 \%(21)$ \\
\hline
\end{tabular}

Key: ? = undetermined sex; SP = sex-pooled. 


\section{Discussion}

One interesting finding of this research was that teeth mean heat-induced dimensional changes varied according to sex. At $900^{\circ} \mathrm{C}$, female teeth dimensions tended to shrink more than male teeth dimensions. If this is a fact and not only an unrepresentative result of this sample, it would mean that pre-existing sex differences in teeth dimensions may be artificially reinforced by burning. In terms of case application, this would not make the metric sex estimation of burned teeth easier because it is difficult, if not impossible, to exactly determine the extent of heat-induced dimensional changes. However, if this result is confirmed in future investigations, it will give more promise to the application of sample-specific methods to samples of teeth that have been subjected to similar heat conditions especially because sex classification results on the unburned sample were poor.

The reasons for this larger heat-induced mean shrinkage in females were not disclosed by our research. Different crown compositions in terms of enamel and dentine have been found for the two sexes though [48]. Males have larger amounts of dentine than females while the reverse is correct for the enamel [48, $73,74]$. This seems to be related to sex chromosomes $[75,76]$ and could theoretically be related to such differences between males and females in terms of heat-induced dimensional changes although we still fail to understand how and why. However, larger female mean heat-induced shrinkage was only clearly observed in the $900^{\circ} \mathrm{C}$ sample, so this hypothesis may not entirely explain sexual differences.

Regrettably, the new root measurements were demonstrated to be unreliable for sex estimation in both the unburned and burned LPM2. Nonetheless, the results have shown that odontometry is not void of potential for the sex estimation of burned human skeletal remains. Although most of the isolated standard measurements revealed small sex classification power, the CEJ-P and the combined CEJ-MD/CEJ-BL measurements allowed for quite successful estimations. One reason was apparently behind that. Heatinduced dimensional changes actually reinforced pre-burning mean sex differences thus leading to a more successful sex classification. Despite heat-induced dimensional changes being very variable, sample specific sex classification was quite successful. This result is quite encouraging and further investigation may help determining if it can be replicated or was merely a random result of our research.

In the case of the combined measurements, most of them showed reasonable potential although only after the experimental burning. The CEJ-BL + CEJ-MD combined measurement was the sole one allowing for successful sex classification above $80 \%$ in both sexes. In this case, sex differences were also artificially enlarged after burning. As seen for the case of the JCE-P, the application of this combined measurement is limited to large samples where sample-specific sex discriminating sectioning points can be calculated. Regrettably, no dimensional feature was demonstrated to reasonably withstand heat-induced dimensional changes and thus serve as a preferential target for odontometric sex estimation. At $900^{\circ} \mathrm{C}$, mere $1.3 \%$ mean shrinkage of the CEJ-P was observed but this value is misleading because a lot of teeth presented heat-induced increase thus balancing the overall mean for dimensional changes. An explanation for such variability in teeth of the same type and burned under the same conditions still escapes us but this experimentation suggests that the factors must be intrinsic to the teeth.

The results obtained in this investigation differentially affect the other three sex estimation approaches. In 
the case of the shrinkage correction factor method [25], the very variable heat-induced dimensional changes (including shrinkage, increase and no change at all) mean that this approach may result in major errors. However, a distinction between CEJ measurements and root dimensions can be established regarding this issue. The former presented a lot more variation in terms of dimensional changes than the latter which have mainly been subjected to shrinkage and only a few cases of increase were documented. Therefore, root measurements are theoretically a more reliable target for shrinkage correction factors. As for the enlarged confidence interval method based on both shrinkage and increase correction factors [11, 25], new data regarding heat-induced dimensional changes are made available by this paper and can be used to calculate the upper and lower bounds of the intervals from now on. The third method is based on the direct application of metric references to burned material [27-29]. Theoretically, the data obtained here could be used for such purpose but very conservative approaches should be adopted due to the differential effect of heat-induced dimensional changes. Probably, only the identification of males with large teeth can be carried out with reasonable certainty.

The failure in using root measurements for sex estimation in unburned remains goes partly against the results from Zorba et al. [52] who found a very significant sexual dimorphism in root height. This may have been due to the use of the LPM2 in this research. Although Zorba et al. [52] and Garn et al. [67, 77] state that it is sexually dimorphic, other authors disagree [17, 39, 78, 79]. Our results have shown that it is indeed sexually dimorphic but that, depending on the measurements, it is often insufficient to achieve successful sex classification. The selection of other teeth may yield better results. Although a large sample of 717 teeth was collected in dentist offices, no other types of teeth were included in this investigation due to their small sample size which would be impeditive of fairly consistent statistical analyses. Nonetheless, it would be interesting to investigate the canine in future research involving burned remains since it has been recurrently pointed out as the most sexually dimorphic human tooth [37, $42,46,53,80-83$ ]. Also, the canine may be easier to recognize than the LPM2 in assemblages composed of burned teeth.

\section{Conclusion}

The results have shown that odontometric analysis for the purpose of sex estimation may be useful when sample-specific methods are created. Regrettably, no feature demonstrated to sufficiently withstand heatinduced dimensional changes. Although the controlled conditions here recreated for the experimental burning do not replicate all archaeological and forensic contexts, they have demonstrated that this research avenue has some potential. As stated above, we do not recommend the application of our values as references for sex estimation. However, the percentages referring to dimensional changes may be useful to examiners who intend to create intervals for more reliable although less precise estimation of the pre-burning dimensions of burned teeth. One predictable challenge regarding this approach will be to estimate the maximum temperature at which the tooth has been subjected to enable the application of those percentages. Besides colour, maximum temperature estimation based on vibrational spectroscopy $[5,84,90]$ or X-ray diffraction [2] may be good options. 
This is one of the few available studies regarding the sexual dimorphism of dental root dimensions. It therefore contributes to its more comprehensive documentation and presented findings that will expectantly have a considerable impact on the analysis of burned human skeletal remains from both archaeological and forensic contexts.

Informed consent was obtained from all individual participants included in the study.

References

1. M.A. Sandholzer, T. Sui, A.M. Korsunsky, A.D. Walmsley, P.J. Lumley, G. Landini, X-ray scattering evaluation of ultrastructural changes in human dental tissues with thermal treatment, J. Forensic Sci. 59 (2014b) 769-774.

2. G. Piga, T.J.U. Thompson, A. Malgosa, S. Enzo, The potential of X-Ray diffraction in the analysis of burned remains from forensic contexts, J. Forensic Sci. 54 (2009) 534-539.

3. L. Rubio, J.M. Sioli, J. Suarez, M.J. Gaitan, S. Martin-de-las-Heras, Spectrophotometric analysis of color changes in teeth incinerated at increasing temperatures, Forensic Sci. Int. 252 (2015) 193.e1193.e6.

4. T.J.U. Thompson, Recent advances in the study of burned bone and their implications for forensic anthropology, Forensic Sci. Int. 146 (2005) 203-205.

5. S. Ellingham, T.J.U. Thompson, M. Islam, G. Taylor, Estimating temperature exposure of burnt bone: A methodological review. Sci. Justice 55 (2015) 181-188.

6. S. Ellingham, T. Thompson, M. Islam, The effect of soft tissue on temperature estimation from burnt bone using fourier transform infrared spectroscopy, J. Forensic Sci. 61 (2016) 153-159.

7. D. Ferembach, I. Schwidetzky, M. Stloukal, Recommendations for age and sex diagnoses of skeletons, J. Hum. Evol. 9 (1980) 517-549.

8. P. Murail, J. Bruzek, F. Houët, E. Cunha, DSP: a tool for probabilistic sex diagnosis using worldwide variability in hip-bone measurements, Bull. Mem. Soc. Anthropol. Paris. 17 (2005) 167-176.

9. J.T. Mayhall, Dental morphology: techniques and strategies, in: M.A. Katzenberg, R.S. Saunders, (Eds.), Biological anthropology of the human skeleton, Wiley-Liss, New York, 2000, pp. 103-130.

10. C. Savio, G. Merlati, P. Danesino, G. Fassin, P. Menghini, Radiographic evaluation of teeth subjected to high temperatures: experimental study to aid identification processes, Forensic Sci. Int. 158 (2006) 108-116.

11. S.F. Fairgrieve, Forensic cremation: recovery and analysis, CRC press, United States, 2008, pp. 1182.

12. J.L. Fereira, Á.E. Fereira, A.I. Ortega, Methods for the analysis of hard dental tissues exposed to high temperatures, Forensic Sci. Int. 178 (2008) 119-124.

13. B. Rai, S.K. Dhattarwal, S.C. Anand, Sex determination from tooth, Medico-Legal Update. 8 (2008) $3-5$. 
14. S. Prabhu, A.B. Acharya, Odontometric sex assessment in Indians, Forensic Sci. Int. 192 (2009) 129.e1-129.e5.

15. R.M.P. Rani, V.G. Mahima, K. Patoil, Bucco-lingual dimension of teeth - An aid in sex determination, J. Forensic Dent. Sci. 1 (2009) 88-92.

16. D.H. Ubelaker, The forensic evaluation of burned skeletal remains: A synthesis, Forensic Sci. Int. 183 (2009) 1-5.

17. A.B. Acharya, P.V. Angadi, S. Prabhu, S. Nagnur, Validity of the mandibular canine index (MCI) in sex prediction: reassessment in an Indian sample, Forensic Sci. Int. 204 (2011) 207.e1-207.e4.

18. J. Viciano, I. Alemán, R. D'Anastasio, L. Capasso, M.C. Botella, Odontometric sex discrimination in the herculaneum sample (79 AD, Naples, Italy), with application to juveniles, Am. J. Phys. Anthropol. 145 (2011) 97-106.

19. T.P. Gocha, H. Schutkowski, Tooth cementum annulation for estimation of age-at-death in thermally altered remains. J. Archaeol. Sci. 58 (2013) 151-155.

20. S. Shankar, K. Anuthama, M. Kruthika, S. Kumar, K. Ramesh, A. Jaheerdeen, M.M. Yasin, Identifying sexual dimorphism in a paediatric South Indian population using stepwise discriminant function analysis, J. Forensic Leg. Med. 20 (2013) 752-756.

21. P. Shipman, G. Foster, M. Schoeninger, Burnt bones and teeth: an experimental study of color, morphology, crystal structure and shrinkage, J. Archaeol. Sci. 11 (1984) 307-325.

22. P.L. Walker, K.P. Miller, R. Richman, Time, temperature, and oxygen availability: an experimental study of the effects of environmental conditions on the color and organic content of cremated bone, in: C.W. Schmidt, S.A. Symes (eds.), The analysis of burned human remains, Academic Press, London, 2008, pp. 55-74.

23. Rubio et al., 2016 - L. Rubio, J.M. Sioli, I. Santos, G.M. Fonseca, S. Martin-de-las-Heras, Alteraciones morfológicas en dientes sometidos a altas temperaturas con interés forense, Int. J. Morphol. 34 (2016) 719-728.

24. Garriga et al., 2016 - J.A. Garriga, D.H. Ubelaker, S.C. Zapico, Evaluation of macroscopic changes and the efficiency of DNA profiling from burnt teeth, Sci. Justice 56 (2016) 437-442.

25. J. Buikstra, M. Swegle, Bone modification due to burning: experimental evidence, in: R. Bonnichsen, M. Sorg (Eds.), Bone Modification, University of Maine, Orono, 1989, pp. 247-258.

26. D. Gonçalves, El muy caliente tema de restos humanos quemados en contextos forenses, in: C.M. Sanabria (Ed.), Antropología y patología forense de la muerte" - la investigación científico-judicial de la muerte y la tortura, desde las fosas clandestinas, hasta la audiencia pública, Forensic Publisher, Bogotá, 2016, pp. 525-552.

27. G.N. Van Vark, W. Amesz-Voorhoeve, A. Cuijpers, Sex-diagnosis of human cremated skeletal material by means of mathematical-statistical and data-analytical methods, Homo. 47 (1996) 305-338.

28. J.K. Wahl. Erfahrungen zur metrishen geschlechtsdiagnose bei leichenbränden, Homo. 47 (1996) 339359.

29. D. Gonçalves, T.J.U. Thompson, E. Cunha, Osteometric sex determination of burned human skeletal remains, J. Forensic Leg. Med. 20 (2013) 906-911.

30. Van Vark, 1974 - G.N. Van Vark, The investigation of human cremated skeletal material by 
multivariate statistical methods I. Methodology, Ossa 1 (1974) 63-95.

31.Van Vark, 1975 - G.N. Van Vark, The investigation of human cremated skeletal material by multivariate statistical methods II. Measures, Ossa 2 (1975) 47-68.

32. Schutkowski and Herrmann, 1983 - H. Schutkowski, B. Herrmann, Zur möglichkeit der metrischen geschlechtsdiagnose an der pars petrosa ossis temporalis, Z. Rechtsmedizin 90 (1983) 219-227.

33. Schutkowski, 1983 - H. Schutkowski, Uber den diagnostischen wert der pars petrosa ossis temporalis fur die geschlechtsbestimmung, Z. Morph. Anthropol 74 (1983) 129-144.

34. Thompson, 2002 - T.J.U. Thompson, The assessment of sex in cremated individuals: some cautionary notes, Can. Soc. Forensic Sci. J. 35 (2002) 49-56.

35. L. Andersen, M. Juhl, T. Solheim, Odontological identification of fire victims-potentialities and limitations, Int. J. Legal Med. 107 (1995) 229-234.

36. I. Pettenati-Soubayroux, M. Signoli, O. Dutour, Sexual dimorphism in teeth: discriminatory effectiveness of permanent lower canine size observed in a XVIIIth century osteological series, Forensic Sci. Int. 126 (2002) 227-232.

37. H. Cardoso, Sample-specific (universal) metric approaches for determining the sex of immature human skeletal remains using permanent tooth dimensions, J. Archaeol. Sci. 35 (2008) 158-168.

38. S. Karkhanis, D. Franklin, Macroscopic and microscopic changes in incinerated deciduous teeth, J. Forensic Odontostomatol. 27 (2010) 9-19.

39. S. Ruengdit, S. Riengrojpitak, M. Tiensuwan, P. Santiwong, Sex determination from teeth size in Thais, Proceedings of the 6th CIFS Academic Day, 14-15th of September, 2011, Impact Muang Thong Thani, Nonthaburi.

40. E. Zorba, K. Moraitis, S.K. Manolis, Sexual dimorphism in permanent teeth of modern Greeks, Forensic Sci. Int. 210 (2011) 74-81.

41. P.V. Angadi, S. Hemani, S. Prabhu, A.B. Acharya, Analyses of odontometric sexual dimorphism and sex assessment accuracy on a large sample, J. Forensic Leg. Med. 20 (2013) 673-677.

42. D. Gonçalves, R. Granja, F. Cardoso, A. Carvalho, Sample-specific sex estimation in archaeological contexts with commingled human remains: a case study from the Middle Neolithic cave of Bom Santo in Portugal, J. Archaeol. Sci. 49 (2014) 185-191.

43. C.F.A. Moorrees, S. Thomsen, E. Jensen, P.K. Yen, Mesiodistal crown diameters of the deciduous and permanent teeth in individuals, J. Dent. Res. 36 (1957) 39-47.

44. S.M. Garn, A.B. Lewis, R.S. Kerewsky, Relationship between buccolingual and mesiodistal tooth diameters, J. Dent. Res. 47 (1968) 495.

45. K.A. Rosenzweig, Tooth form as a distinguishing trait between sexes and human populations, J. Dent. Res. 49 (1970) 1423-1426.

46. M.Y. Iscan, P.S. Kedici, Sexual variation in bucco-lingual dimensions in Turkish dentition, Forensic Sci. Int. 1 (2003) 160-164.

47. S. Kondo, G.C. Townsend, Sexual dimorphism in crown units of mandibular deciduous and permanent molars in Australian Aborigines, Homo. 55 (2004) 53-64.

48. G.T. Schwartz, C. Dean, Sexual dimorphism in modern human permanent teeth, Am. J. Phys. Anthropol. 128 (2005) 312-317. 
49. J.Y.K. Ling, R.W.K. Wong, Tooth dimensions of southern Chinese, Homo. 58 (2007) 67-73.

50. C. Pereira, M. Bernardo, M.C. Mendonça, Contribution of teeth in human forensic identification Discriminant function sexing odontometrical techniques in Portuguese population, J. Forensic Leg. Med. 17 (2010) 105-110.

51. J. Morgan, Metric sexual dimorphism in permanent canines, Bull. Int. Assoc. Paleodont. 5 (2011) 412.

52. E. Zorba, V. Vanna, K. Moraitis, Sexual dimorphism of root length on a Greek population sample, Homo. 65 (2014) 143-154.

53. J.V. Hosmani, R.S. Nayak, V.S. Kotrashetti, S. Pradeep, D. Babji, Reliability of mandibular canines as indicators for sexual dichotomy, J. Int. Oral Health. 5 (2013) 1-7.

54. S.M. Garn, W.L. Van Alstine, P.E. Cole, Relationship between root lengths and crown diameters of corresponding teeth, J. Dent. Res. 57 (1978) 636.

55. D. H. Goose, Dental measurement: an assessment of its value in anthropological studies, in: S. Hillson (Ed.) Dental Anthropology, Cambridge University Press, Cambridge, 2002, pp. 125-148.

56. S. Hillson, C. FitzGerald, H. Flinn, Alternative dental measurements: proposals and relationships with other measurements, Am. J. Phys. Anthropol. 126 (2005) 413-426.

57. M. Teschler-Nicola, H. Prossinger, Sex determination using tooth dimensions, in: K.W. Alt, F.W. Rosing, M. Teschler-Nicola (Eds.), Dental Anthropology: Fundamentals, Limits, and Prospects, Springer Vienna, Vienna, 1998, pp. 479-500.

58. B. Hassett, Estimating sex using cervical canine odontometrics: a test using a known sex sample, Am. J. Phys. Anthropol. 146 (2011) 486-489.

59. C.W. Schmidt, The recovery and study of burned human teeth, in: C.W. Schmidt, S.A. Symes (Eds.) The analysis of burned human remains, Academic Press, London, 2008, pp. 55-74.

60. A.J. Hill, R. Lain, I. Hewson, Preservation of dental evidence following exposure to high temperatures, Forensic Sci. Int. 205 (2011) 40-43.

61. P. Tuttösí, H.F. Cardoso, An assessment of sexual dimorphism and sex estimation using cervical dental measurements in a Northwest Coast archeological sample, J. Archaeol. Sci. 3 (2015) 306-312.

62. Herrmann, 1977 - B. Herrmann, On histological investigations of cremated human remains, J. Hum. Evol. 6 (1977) 101-102.

63. M. Sandholzer, A. Walmsley, P. Lumley, G. Landini, Radiologic evaluation of heat-induced shrinkage and shape preservation of human teeth using micro-CT, J. Forensic Radiol. Imaging. 1 (2013) 107-111.

64. S.M. Garn, P.E. Cole, W.L. Van Alstine, Sex discriminatory effectiveness using combinations of root lengths and crown diameters, Am. J. Phys. Anthropol. 50 (1979) 115-118.

65. T.K. Black, Sexual dimorphism in the tooth-crown diameters of the deciduous teeth, Am. J. Phys. Anthropol. 48 (1978) 77-82.

66. C. De Vito, S.R. Saunders, A discriminant function analysis of deciduous teeth to determine sex [resumo], J. Forensic Sci. 35 (1990) 845-858.

67. S.M. Garn, P.E. Cole, R.L. Wainwright, K.E. Guire, Sex discriminatory effectiveness using combinations of permanent teeth, J. Dent. Res. 56 (1977) 697. 
68. E.F. Harris, M.T. Nweeia, Tooth size of Ticuna Indians, Colombia, with phenetic comparisons to other Amerindians, Am. J. Phys. Anthropol. 53 (1980) 81-91.

69. A.C. Solari, K. Abramovitch, The accuracy and precision of third molar development as an indicator of chronological age in Hispanics, J. Forensic Sci. 47 (2001) 531-535.

70. O.T. Yamaguto, M.H.F. Vasconcelos, Determinação das medidas dentárias mésio-distais em indivíduos brasileiros leucodermas com oclusão normal, R. Dental Press. Ortodon. Ortop. Facial. 10 (2005) 99-107.

71. S.J. Ulijaszek, J.A. Lourie, Intra- and inter-observer error in anthropometric measurement, in: S.J. Ulijaszek, C.G.N. Mascie-Taylor (Eds.) Anthropometry: the individual and the population, Cambridge University Press, Cambridge, 1994, pp. 30-35.

72. J. Albanese, H.F.V. Cardoso, S.R. Saunders, Universal methodology for developing univariate sample-specific sex determination methods: An example using the epicondylar breadth of the humerus, J. Archaeol. Sci. 32 (2005) 143-152.

73. E.F. Harris, J.D. Hicks, A radiographic assessment of enamel thickness in human maxillary incisors, Arch. Oral. Biol. 43 (1998) 825-831.

74. U. Zilberman, P. Smith, Sex- and age-related differences in primary and secondary dentin formation, Adv. Dent. Res. 15 (2001) 42-45.

75. L. Alvesalo, E. Tammisalo, Enamel thickness in 45, X females' permanent teeth, Am. J. Hum. Genet. 33 (1981) 464-469.

76. L. Alvesalo, E. Tammisalo, E. Therman, 47, XXX females, sex chromosomes, and tooth crown structure, J. Hum. Genet. 77 (1987) 345-348.

77. S.M. Garn, R.S. Kerewsky, D.R. Swindler, Canine "field” in sexual dimorphism of tooth size, Nature. 212 (1966a) 1501-1502.

78. D.A. Lunt, Odontometric study of medieval Danes, J. Dent. Res. 46 (1967) 918-922.

79. S.E. Bishara, J.R. Jakobsen, E.M. Abdallah, A. Fernandez Garcia, Comparisons of mesiodistal and buccolingual crown dimensions of the permanent teeth in three populations from Egypt, Mexico, and the United States, Am. J. Orthod. Dentofac. 96 (1989) 416-422.

80. F.W. Rosing, Sexing immature human skeletons, J. Hum. Evol. 12 (1982) 149-155.

81. F.N. Hattab, S. Al-Khateeb, I. Sultan, Mesiodistal crown diameters of permanent teeth in Jordanians, Arch. Oral. Biol. 41 (1996) 641-645.

82. K.K. Yuen, E.L. Tang, L.L. So, Relations between the mesiodistal crown diameters of the primary and permanent teeth of hong kong Chinese, Arch. Oral Biol. 41 (1996) 1-7.

83. M. Vodanovic, Z. Demo, V. Njemirovskij, J. Keros, H. Brkic, Odontometrics: a useful method for sex determination in an archaeological skeletal population?, J. Archaeol. Sci. 34 (2007) 905-913.

84. T.J.U. Thompson, M. Islam, M. Bonniere, A new statistical approach for determining the crystallinity of heat-altered bone mineral from FTIR spectra, J. Archaeol. Sci. 40 (2013) 416-422.

85. M.A. Sandholzer, K. Baron, P. Heimel, B.D. Metscher, Volume analysis of heat-induced cracks in human molars: A preliminary study, J. Forensic Dent. Sci. 6 (2014a) 139-144.

86. K.A. Murray, J.C. Rose, The analysis of cremains: A case study involving the inappropriate disposal of mortuary remains, J. Forensic Sci. 38 (1993) 98-103. 
87. J.D. Purves, Dental identification of fire victims, Forensic Sci. 6 (1975) 217-219.

88. P.M. Mayne Correia, Fire modification of bone: a review of the literature, in: W.D. Haglund, M.H. Sorg (Eds.) Forensic Taphonomy: The post-mortem fate of human remains, CRC Press, Boca Raton FL, 1997, pp. 275-293.

89. T.J.U. Thompson, Recent advances in the study of burned bone and their implications for forensic anthropology, Forensic Sci. Int. 146S (2004) S203-S205.

90. Piga et al., 2016 - G. Piga, D. Gonçalves, T.J.U. Thompson, A. Brunetti, S. Enzo, A. Malgosa, The advantage of combining ATR-IR and XRD analyses of burned skeletal remains for the estimation of maximum temperature, Int. J. Spectrosc. (2016) DOI: http://dx.doi.org/10.1155/2016/4810149. 